\title{
Dynamic Properties of Impulse Measuring Systems
}

Pedersen, A.; Lausen, P.

Published in:

IEEE Transactions on Power Systems

Link to article, DOI:

10.1109/TPAS.1971.292983

Publication date:

1971

Document Version

Publisher's PDF, also known as Version of record

Link back to DTU Orbit

Citation (APA):

Pedersen, A., \& Lausen, P. (1971). Dynamic Properties of Impulse Measuring Systems. IEEE Transactions on Power Systems, 90(3), 1424-1432. https://doi.org/10.1109/TPAS.1971.292983

\section{General rights}

Copyright and moral rights for the publications made accessible in the public portal are retained by the authors and/or other copyright owners and it is a condition of accessing publications that users recognise and abide by the legal requirements associated with these rights.

- Users may download and print one copy of any publication from the public portal for the purpose of private study or research.

- You may not further distribute the material or use it for any profit-making activity or commercial gain

- You may freely distribute the URL identifying the publication in the public portal

If you believe that this document breaches copyright please contact us providing details, and we will remove access to the work immediately and investigate your claim. 


\title{
DYNAMIC PROPERTIES OF IMPULSE MEASURING SYSTEMS
}

\author{
Aa. Pedersen \& P. Lausen \\ Senior Member, IEEE $\quad$ Non Member, IEEE \\ The High Voltage Laboratory, \\ Electric Power Engineering Department, Technical University of Denmark.
}

\begin{abstract}
After some basic considerations the dynamic properties of the measuring system are subjected to a general examination based on a number of responses, characteristic of the system. It is demonstrated that an impulse circuit has an internal impedance different from zero, for which reason the interaction between the generator and the measuring circuit is of paramount importance to the voltage across the test object. Based on the measured values the determination of the applied voltage is considered.
\end{abstract}

For design purposes the properties of impulse measuring systems are finally discussed based on the characteristic responses.

\section{INTRODUCTION}

The evaluation of the result of any kind of measurement presupposes an analysis of the following problems:

How correctly does the measurement represent the measured quantity?

How does the measuring system influence the quantity to be measured?

The solution of the first problem demands an examination of the accuracy, sensitivity, and stability of the measuring system - properties that will receive no further comment in the present paper. Measurements $\cong$ quantities that vary as a function of time, furthermore demand a determination of the dynamic properties of the system.

The influence of the measuring system on the quantity to be measured is caused by an interaction between the measuring and the generating systems. Consequently both systems must be examined.

Based on this general concept the following paragraphs will deal exclusively with measurements of dynamic phenomena, especially high voltage impulses.

\section{GENERAL CONSIDERATIONS ON MEASURING SYSTEMS}

\section{Impedances of Measuring Systems.}

If the measuring system consists of linear elements the principle of superposition is applicable with the consequence that it is possible to determine any given input as a function of one or more specific inputs, and the measured response as the same function of the responses to the specific inputs. Therefore, the measuring system may be considered as a "black box" with two input and two output terminals, allowing all transfer properties and loading characteristics to be determined by measurements on the terminals of this system, regardless of any present knowledge of the network.

If non-linear elements are included, the principle of superposition does not apply any longer. Consequently, the response to any given input must be determined on the basis of the input itself, either by measurement or by calculation. The latter, however, is only possible if a completely equivalent network for the system can be established, for which the individual elements and their amplitude dependency are known, such as $c=f(u), l=f(i), r=f(u)$ or $r=f(i)$. For any practical purpose calculations on the system can be performed by numerical

Paper 70 TP 605-PWR, recommended and approved by the Power System Instrumentation and Measurements Committee of the IEEE Power Group for presentation at the IEEE Summer. Power Meeting and EHV Conference, Los Angeles, Calif., July 12-17, 1970. Manuscript submitted March 27, 1970; made available for printing May 4, 1970. methods only. In addition to amplitude dependent non-linearity the elements may show hysteresis, which will cause a further limitation of the practical possibility of calculation.

Voltage dependent elements caused by partial discharges (corona) occur in impulse measuring systems. In most cases it will be permissible to ignore such non-linearities since they are of importance only in connexion with measurements of fast phenomena (in the ns range). If, however, an evaluation of this approximation is requested, the measuring system must be examined at low voltages without partial discharges as well as at high voltages where such partial discharges occur. For the purpose of calculation the non-linear elements arein practice substituted by suitably chosen linear elements depending on the magnitude of the input. In such cases the calculated results must always be checked by measurements in order to ascertain whether a sufficiently good approximation has been obtained in the actual case. - The following paragraphs are based on the presupposition that the measuring system consists of linear elements.

For the purpose of evaluating the performance of the measuring system by calculation it is necessary to establish a sufficiently accurate equivalent network. If transmission lines are present, or if the measuring system has a significant physical extension, it will be necessary to make use of distributed parametres - represented by an infinite number of elements in the equivalent network - in order to account for all frequencies.

Transmission lines or components of the length $\mathrm{L}$ may always be substituted by concentrated elements when

$$
L \ll \frac{v}{f}
$$

v the velocity of light in the medium in question.

f the highest frequency of interest for the measurement.

However, it may often be advantageous to consider transmission lines separately by using the travelling wave concept, as known from the transmission theory, for these parts of the system in order to evaluate the time function of the output from the complete measuring system.

The voltage between the input terminals of the measuring system can be expressed by the following general equation in Laplace notation with $\mathrm{s}$ as the Laplace operator:

$$
\mathrm{U}_{\mathrm{l}}(\mathrm{s})=\mathrm{U}_{\mathrm{g}}(\mathrm{s}) \frac{\mathrm{Z}_{\mathrm{m}}(\mathrm{s})}{\mathrm{Z}_{\mathrm{i}}(\mathrm{s})+\mathrm{Z}_{\mathrm{m}}(\mathrm{s})}
$$

$\mathrm{U}_{\mathrm{l}}(\mathrm{s})$ the voltage across the input terminals of the measuring system.

$\mathrm{U}_{\mathrm{g}}(\mathrm{s})$ the voltage generated in the system.

$\mathrm{Z}_{\mathrm{i}}(\mathrm{s})$ the internal impedance of the generating system as seen from the input terminals of the measuring system.

$\mathrm{Z}_{\mathrm{m}}$ (s) the impedance of the measuring system as seen from the input terminals of the measuring system.

Based on this equation, table I lists the only cases in which connexion of a measuring system will have no influence on the quantity to 
be measured. In the special case when $\mathrm{Z}_{\mathrm{i}}(\mathrm{s})$ and $\mathrm{Z}_{\mathrm{m}}(\mathrm{s})$ are proportional the connexion of the measuring equipment will only give rise to a proportional change in the amplitude of the quantity to be measured. This case, however, is mostly of academic interest.

Table I. Special cases when connexion of the measuring equipment will not affect the quantity to be measured.

\begin{tabular}{|c|c|}
\hline Current Measurements & Voltage Measurements \\
\hline$z_{i}=\infty$ & $\mathrm{z}_{\mathbf{i}}=0$ \\
\hline $\begin{array}{l}\text { i.e. the generator re- } \\
\text { presents an ideal } \\
\text { source of current sup- } \\
\text { ply. }\end{array}$ & $\begin{array}{l}\text { i.e. the generator re- } \\
\text { presents an ideal } \\
\text { source of voltage sup- } \\
\text { ply. }\end{array}$ \\
\hline $\mathrm{z}_{\mathrm{m}}=0$ & $\mathrm{Z}_{\mathrm{m}}=\infty$ \\
\hline \multicolumn{2}{|c|}{$\begin{array}{l}\text { In most practical cases fulfilment of the fol- } \\
\text { lowing requirements will suffice: }\end{array}$} \\
\hline $\mathrm{z}_{\mathrm{m}} \ll \mathrm{z}_{\mathrm{i}}$ & $z_{m} \gg z_{i}$ \\
\hline
\end{tabular}

For certain types of measurement (including impulse voltage measurements) the measuring equipment is a permanent part of the system. The problem is therefore limited to generation of the required voltage within a given accuracy with the measuring equipment in situ.

\section{The Transfer Properties of the Measuring System.}

The transfer properties of measuring systems consisting of linear elements only, can be determined from the amplitude and phasefrequency characteristics for the system (i.e. based on a number of specific steady-state responses), or from the unit step response for the system (i.e. based on one specific transient response). These methods for the determination of transfer properties are two out of several possible, but in practice they are used exclusively - as a consequence of the existing mathematical tools for the treatment of information in these forms.

The amplitude and phase-frequency characteristics determine the signal ratio for the measuring system, defined as the ratio between the input and the output voltage for a sine wave of specific frequency. The unit step response determine the normalizing factor for the measuring system, defined as the ratio between the unit step and a selected part of the unit step response (normally the asymptotic value).

The unit step may be described by means of the cyclic frequency by the equation:

$$
\mathrm{U}=\frac{1}{2}+\frac{1}{\pi} \int_{0}^{\infty} \frac{\sin \omega \mathrm{t}}{\omega} \mathrm{d} \omega
$$

Thus the unit step response of the system contains information about the transfer properties of the system for all frequencies from 0 to $\infty$ on an integrated form, while the amplitude and phase-frequency characteristics contain the same information determined frequency by frequency. The information can be transformed mathematically ${ }^{1,2}$ from one form to the other.

Steady-state phenomena, such as singular frequencies or periodic functions - which via a Fourier expansion can be resolved into harmonics - are often examined by means of the frequency characteristics. In measurements of transient phenomena, where expansion into sine functions gives a continuous frequency spectrum as opposed to the line spectrum of the Fourier series $\dagger$ ), it will usually be profitable to describe the applied phenomenon as a function of the unit step and the response of the system as the same function of the unit step response.

It is always possible to determine the output when the input and the transfer properties of the measuring system are known, whereas in general it is impossible in practice to reverse the procedure since the measuring system will cause a loss of information. The lost information cannot be regenerated, and the determination of the input on the basis of the measured output therefore presupposes a certain advance knowledge of the input.

3. Determination of the Dynamic Properties of the Measuring System by Means of the Unit Step Response.

The unit step response is determined as the system's reproduction of an applied unit step. In Laplace notation the following equation is valid:

$$
\mathrm{G}(\mathrm{s})=\frac{1}{\mathrm{~s}} \mathrm{H}(\mathrm{s})
$$

$\mathrm{G}(\mathrm{s})$ the unit step response.

$\frac{1}{\mathrm{~s}} \quad$ the unit step.

H(s) the transfer function of the system. to be:

The response, $\mathrm{U}_{2}(\mathrm{~s})$, to an arbitrary input voltage, $\mathrm{U}_{1}(\mathrm{~s})$, is found

$$
\mathrm{U}_{2}(\mathrm{~s})=\mathrm{U}_{1}(\mathrm{~s}) \cdot \mathrm{H}(\mathrm{s})=\mathrm{U}_{1}(\mathrm{~s}) \cdot \mathrm{s} \cdot \mathrm{G}(\mathrm{s})
$$

Thus the unit step response implicitly contains the transfer function. The shape of the unit step response directly gives some information about the measuring system. The front steepness is a measure for the limit frequency, oscillations show the resonance frequencies, and the magnitude determines the normalizing factor of the measuring system.

The area between the unit step and the normalized unit step response is called the measuring system's response time, $\mathrm{T}_{\mathrm{N}}$, which is defined by the equation:

$$
\mathrm{T}_{\mathrm{N}}=\int_{\mathrm{O}}^{\infty}(1-\mathrm{g}(\mathrm{t})) \mathrm{dt}
$$

$g(t)$ the voltage time function of the normalized unit step response.

As an example the use of the unit step response for the determination of the response to a dynamic phenomenon is demonstrated by a measuring system's reproduction of a linearly rising input with the steepness $S=1$ ( (fig. 1). After a certain time, $T_{q}$, when the unit step

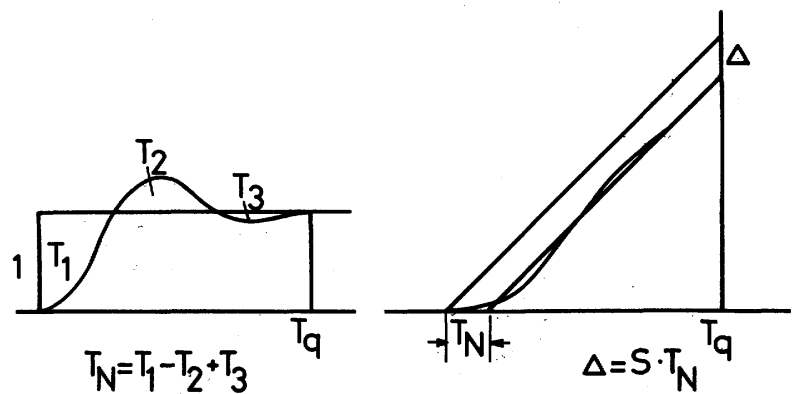

Fig. 1. The response of a measuring system to a linearly rising input.

$\dagger$ ) It should be noted, that a transient phenomenon can be described with arbitrary accuracy by a line spectrum, provided that the basic frequency of this spectrum is chosen sufficiently low. 
response has attained the value 1 , the difference at a given time, $t$, will be constantly equal to the system's response time, $\mathrm{T}_{\mathrm{N}}$, and the measured voltage will be displaced by the time $T_{N}$ as compared to the applied voltage. If the steepness of the voltage is different from 1, e.g. S, the amplitude difference between the applied and the measured voltage after the time $T_{q}$ will be $S \cdot T_{N}$, while the displacement in time will always be equal to the response time $\mathrm{T}_{\mathrm{N}}$.

\section{MEASURING SYSTEMS FOR IMPULSE VOLTAGES}

A measuring system for impulse voltages must reproduce the potential difference between 2 points separated in space, as a function of time. The measured voltages go up to megavolts and the time involved goes down to nanoseconds. One of the two points will usually be on ground potential, in which case it will be connected to the grounding system of the measuring arrangement. The high voltages involve a great distance between the terminals of the test object as well as voltage dividers of great height and divider ratio. This makes it difficult to design measuring systems with high limit frequencies. The high level and fast changes of the voltages together with the associate currents in the system at the same time represent a risk of erroneous measurements due to signals introduced into the system at other places than the input terminals (noise). This fact is mentioned only for the sake of completion, and it may be added that the accompanying problems have not been clarified in detail so far.

In the following paragraphs the dynamic properties of the impulse measuring system are described through an analysis of the response properties of the system.

\section{The Components of the Measuring System.}

For the investigation of the behaviour of a measuring system it will usually be of advantage to divide the system into two parts - the lead and the rest of the system - where the lead is dealt with separately according to the rules of the transmission theory. Afterwards the transfer in the rest of the measuring system is determined on the basis of these results.

In the following paragraphs only measuring systems without damping resistor in the lead $\dagger$ ) will be examined, and in accordance with the procedure above such systems will be divided into:

The lead with the grounding system of the measuring system as return path.

The part of the measuring system loading the lead at the divider end, i.e. voltage divider, measuring cable, registrating instrument, etc, in the actual arrangement - viz. the complete voltage divider hereinafter referred to as the terminator.

The surge impedance, $\mathrm{Z}$, for the measuring lead will usually be in the order of $400-500 \Omega$, and the propagation velocity, $\mathrm{v}$, will be equal to the velocity of light, $30 \mathrm{~cm} / \mathrm{ns}$.

The impedance of the terminator as seen fr $m$ the lead will mainly be determined by the elements of the voltage divider. Voltage dividers usually consist of resistors and/or capacitors. Depending upon the elements employed the voltage dividers are termed:

- resistor dividers,

- capacitor dividers, or

- mixed dividers, consisting of resistors parallel to or in series with capacitors.

The impedance of the terminator will vary as a function of the frequency, except when the impedance is equivalent to a pure resistance. In Laplace notation the impedance of the terminator, as a function of the operator $s$, is $Z_{t}(s)$, where

$$
\mathrm{Z}_{\mathrm{t}}(\mathrm{s})=\frac{\mathrm{U}(\mathrm{s})}{\mathrm{I}(\mathrm{s})}
$$

†) For measuring systems with damping resistor in the lead, cf. lit. 3.
$\mathrm{U}(\mathrm{s})$ the voltage across the terminator.

I(s) the current input to the terminator.

For a given voltage input, $u(t)$, associated with the current, $i(t)$, an "impedance" can be defined as:

$$
z_{t}(t)=\frac{u(t)}{i(t)}
$$

It may often be convenient to use this time dependent "impedance" for the evaluation of the reflections and the load associated with a given input.

Measuring systems for fast impulse voltages usually utilize either resistor dividers, often shielded to improve the capacitive voltage distribution, or mixed dividers with resistors and capacitors in series, for which the "impedance" to a unit step in the first moment primarily is determined by the series resistance.

\section{The Unit Step Response of the Measuring System.}

As an example of the application of the travelling wave concept the unit step response is determined for the measuring system shown in fig. 2 and consisting of a lead of the length $L$ with the surge impedance $Z$, and a terminator $T$ which is assumed to be ideal, i.e. the measured output voltage is a true copy of the voltage across the terminator.

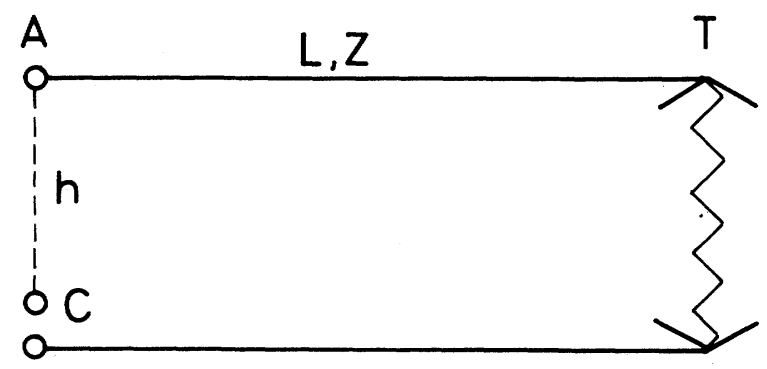

B

Fig. 2. Measuring system with a terminator.

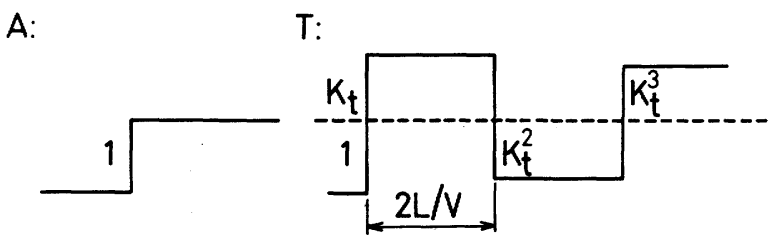

Fig. 3. Unit step response of a measuring system with a pure resistive terminator; $\mathrm{K}_{\mathrm{t}}=0.9$.

The "impedance" of the system (fig. 2) as seen from A will be equal to $\mathrm{Z}$ for two times the travel time on the lead, after which it will change, dependent on the input and the "impedance" of the terminator. The change of this "load impedance" implies that the generator generating the unit step between A and B must have a zero impedance.

In the example the terminator is assumed to be purely resistive. The unit step applied between A and B will travel along the lead to the terminator. Since $\mathrm{R} \neq \mathrm{Z}$, a reflection will be generated here, determined by the reflection coefficient:

$$
\mathrm{K}_{\mathrm{t}}=\frac{\mathrm{R}-\mathrm{Z}}{\mathrm{R}+\mathrm{Z}}
$$

The reflection will travel back to A where the zero impedance generator will send back a similar but inverted wave to the terminator, since the reflection coefficient $\mathrm{K}_{\mathrm{g}}=-1$. After 2 times the travel time on the lead, 
$2 \frac{\mathrm{L}}{\mathrm{V}}$, this wave will reach the terminator, and a new reflection will be generated, moving in the direction of $\mathrm{A}$. The voltage at $\mathrm{A}$ and $\mathrm{T}$ is shown in fig. $3 . \dagger$ ).

The response time of the system, which emanates exclusively from the lead, is found from fig. 3 to be:

$$
\mathrm{T}_{\mathrm{L}}=-2 \frac{\mathrm{L}}{\mathrm{v}} \mathrm{K}_{\mathrm{t}}\left(1-\mathrm{K}_{\mathrm{t}}+\mathrm{K}_{\mathrm{t}}^{2}-\mathrm{K}_{\mathrm{t}}^{3}+\ldots . .\right)=-2 \frac{\mathrm{L}}{\mathrm{v}} \frac{\mathrm{K}_{\mathrm{t}}}{1+\mathrm{K}_{\mathrm{t}}}
$$

The voltage at $\mathrm{T}$, however, will be oscillating.

In practice the input terminals of the measuring system, $\mathrm{A}$ and $\mathrm{B}$, are placed at a great distance from each other. Determination of the unit step response by measurement requires a zero impedance generator placed between these two points. Unfortunately, the realization of such a generator is impossible when the points are separated in space. Therefore, the system is modified by a vertical lead AC (marked by a dotted line on fig. 2). The distance between $B$ and $C$ is chosen so short that a zero impedance generator between the two.points with sufficiently good approximation can be realized. The unit step response of the modified system can be measured directly, whereas this measurement cannot be executed on the true measuring system. On the other hand, it is possible to determine the response time for the true system, since it has been demonstrated ${ }^{3}$ that the vertical lead $\mathrm{AC}$ gives a negative contribution, $T_{h}$, to the response time, of the magnitude:

$$
\mathrm{T}_{\mathrm{h}}=2 \frac{\mathrm{h}}{\mathrm{v}} \frac{\mathrm{K}_{\mathrm{t}}(\mathrm{o})}{1+\mathrm{K}_{\mathrm{t}}(\mathrm{o})}
$$

$\mathrm{K}_{\mathrm{t}}(\mathrm{o})$ the reflection coefficient at the terminator for the time $t \rightarrow \infty$.

$h$ the length of the added lead.

$\mathrm{v}$ the velocity of light.

The determination of the response time for an oscillating unit step response will be encumbered with great uncertainty, since the response time is found by subtraction of almost equally great areas. In practice the response time for such systems therefore must be determined either by means of the CIGRE volt-time curve or by an indirect method.

3. Determination of Response Time Based on CIGRE's Volt-Time Curve.

As demonstrated earlier, the response of a measuring system after a certain time will follow a linearly rising impulse at a time distance

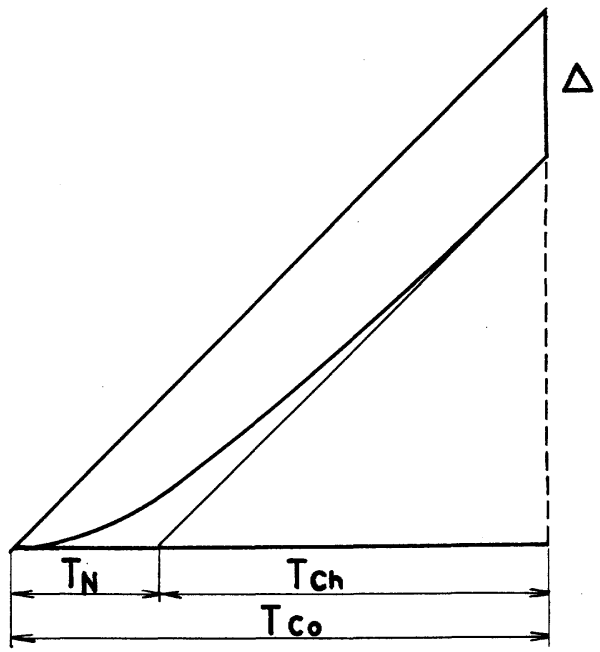

Fig. 4. Response of a measuring system to a linearly rising input.

$\dagger$ ) In the following paragraphs the time of the beginning of input and responses is set at $t=0$, the time-lag caused by the lead having been left out of account. equal to the response time of the system, $T_{N}$ (fig. 4).

Thus it is possible to determine the response time $T_{N}$ by a measurement of the breakdown of a welldefined gap for which the relation between the steepness of an applied, linearly rising voltage and the time to breakdown, $\mathrm{T}_{\mathrm{Co}}$, are known.

CIGRE's (Conférence Internationale des Grande Réseaux Électriques) Study Committee No. 8 has induced a number of laboratories throughout the world to determine the volt-time curve for a $60 \mathrm{~mm}$ sphere gap with $25 \mathrm{~cm}$ spheres subjected to a negative, lineary rising voltage with the steepness $S$, in accordance with a specified procedure $^{4,5}$.

The established graph, stated to have an accuracy within $\pm 5 \mathrm{~ns}$, is shown in fig. 5 .

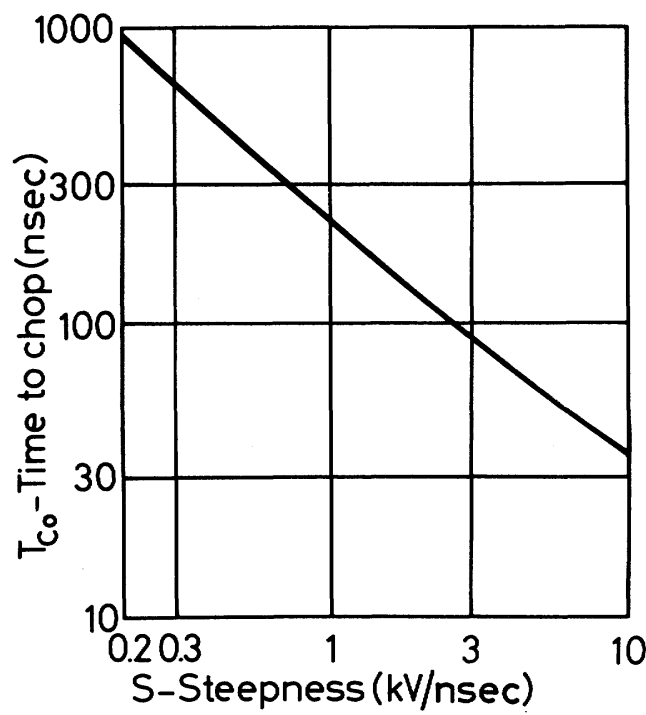

Fig. 5. The CIGRE volt-time curve. (Lit. 5).
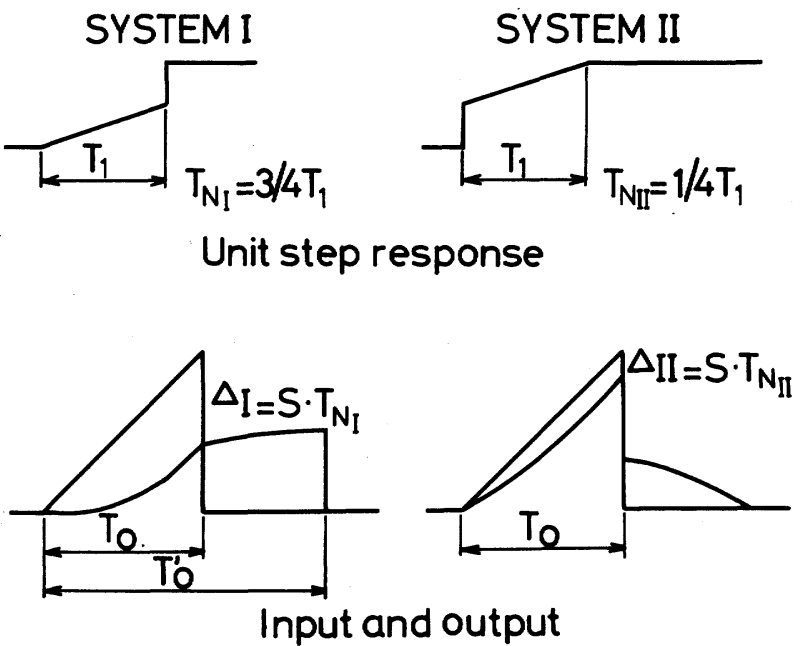

Fig. 6. Responses of measuring systems I and II to a linearly rising voltage chopped momentarily at $\mathrm{T}_{\mathrm{O}}$.

If the measured time to breakdown, $\mathrm{T}_{\mathrm{Ch}}$, is defined as shown in fig. 4 , the response time of the measuring system will be

$$
\mathrm{T}_{\mathrm{N}}=\mathrm{T}_{\mathrm{Co}}-\mathrm{T}_{\mathrm{Ch}}
$$

$\mathrm{T}_{\mathrm{Co}}$ true time to breakdown.

$\mathrm{T}_{\mathrm{Ch}}$ measured time to breakdown.

If the response time $T_{N}$ has to be determined by means of the CIGRE volt-time curve, it must be possible to pinpoint the correct time for the 
breakdown on the measured wave form. In practice this is not always easy to do by simple means. As an example the responses to a linearly rising voltage chopped momentarily at the time $T_{0}$ have been constructed in fig. 6 with the shown simplified unit step responses of the measuring systems I and II.

It will be impossible without advance knowledge of the unit step response for system $I$ to determine $T_{O}$, whereas system II reproduces the applied voltage in an immediately accessible form, even though the two step responses consist of the same two basic components, only in system I added with a time delay.

The determination of the response time by means of the CIGRE volt-time curve is easy and elegant to perform in the laboratory. However, this method must always be supplemented by other measurements on the measuring system examined, since it must be verified that the measuring system follows the applied, linearly rising voltage before the time to chop, and that this can be determined in a simple manner from the measured output voltage. Furthermore, it is necessary to use rather steep impulses for the determination of the response time with sufficient accuracy, and therefore the method is only applicable for fast measuring systems.

\section{Indirect Method of Response Time Determination.}

The oscillation on the unit step response of the measuring system caused by the high voltage lead will disappear if the zero impedance generator is replaced by a generator with an internal impedance equal to the surge impedance of the lead. Such a generator can be realized by a series connexion of a zero impedance generator and either a resistor equal to the surge impedance of the measuring lead, or a measuring lead of infinite length and constant surge impedance. Hence the term "infinite-line" measurement which will be used in the following paragraphs.

The "infinite-line" response time, $\mathrm{T}_{\infty}$, is defined as the area between a unit step generated behind the internal impedance of the "infinite-line" generator, and the normalized response of the terminator. $\mathrm{T}_{\infty}$ can be determined by measurement with good accuracy, because the response has no oscillations.

For measuring systems without damping resistor in the lead the "infinite-line" response time is ${ }^{3}$ :

$$
\mathrm{T}_{\infty}=\mathrm{T}_{\mathrm{kt}}+\mathrm{T}_{\mathrm{t}}
$$

$\mathrm{T}_{\mathrm{kt}}$ the response time of the reflection at the terminator defined as, the area between the unit step of the "infiniteline" measurement and the normalized voltage across the terminator (the reflection response).

$\mathrm{T}_{\mathrm{t}}$ the response time of the transfer through the terminator defined as, the area between a unit step applied to the terminator and the normalized response of the latter.

The response time for the reflection from the terminator, $\mathrm{T}_{\mathrm{kt}}$, can be determined by a measurement of the voltage across the internal

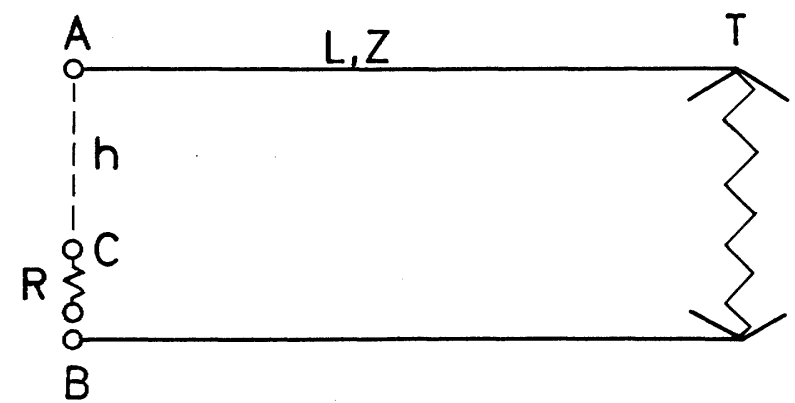

Fig. 7. Arrangement for "infinite-line" measurement. R equal to the surge impedance of the measuring lead at point $C$. impedance of the generator ( $\mathrm{R}$, fig. 7), since the voltage across this resistor after 2 times the travel time is a true copy of the voltage across the terminator.

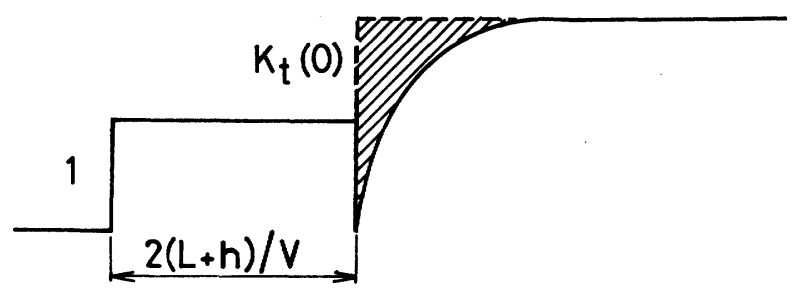

Fig. 8. Voltage across R. (Cf. fig. 7).

In fig. 8 is shown the voltage wave across $R$ for a terminator consisting of a capacitance, $C_{t}$, in parallel with a resistance, $R_{t} \gg Z$.

The hatched area on normalized form determines the response time for the reflection coefficient at the terminator.

$$
\mathrm{T}_{\mathrm{kt}}=\frac{\mathrm{A}}{1+\mathrm{K}_{\mathrm{t}}(\mathrm{o})}
$$

$\mathrm{K}_{\mathrm{t}}(\mathrm{o})$ the reflection coefficient at the terminator for the time $t \rightarrow \infty$.

If $\mathrm{T}_{\infty}$ and $\mathrm{T}_{k t}$ are known the response time for the transfer through the terminator, $T_{t}$, can be calculated.

If $T_{t}$ is known the unit step response time, $T_{N}$, can be calculated, since it can be demonstrated ${ }^{3}$ that

$\mathrm{T}_{\mathrm{N}}=\mathrm{T}_{\mathrm{t}}-2 \frac{\mathrm{L}}{\mathrm{v}} \cdot \frac{\mathrm{K}_{\mathrm{t}}(\mathrm{o})}{1+\mathrm{K}_{\mathrm{t}}(\mathrm{o})}$

$T_{t}$ the response time for the transfer through the terminator.

$\mathrm{L}$ the length of the measuring lead.

$\mathrm{v}$ the velocity of light.

$\mathrm{K}_{\mathrm{t}}(\mathrm{o})$ the reflection coefficient at the terminator for the time $t \rightarrow \infty$.

This procedure for the determination of $T_{N}$ is far more accurate than measurement of the unit step response of the modified system. Furthermore, the method implies determination of the response time for the transfer through a terminator, and thus allows a determination of the response time for measuring systems without leads.

Measurement of the responses and response times mentioned in this section gives rise to practical measuring problems which shall receive no further comments in this paper.

\section{The Internal Impedance of the Impulse Circuit.}

The voltage across the test object in an impulse circuit depends upon the voltage generated as well as on the interaction between the generating and measuring circuits. As a demonstration the voltage across the test object and the response of the system to this influence are calculated in two examples shown in fig. 9 for generators with $Z_{i}=0$ and $\mathrm{Z}_{\mathrm{i}}=\mathrm{Z}$, for a unit step as well as for a linearly rising voltage. The terminator of the employed measuring system is assumed to have the impedance $\mathrm{Z}_{\mathrm{t}}=\infty$, and to give an exact reproduction of the voltage across the terminator.

In neither case the measuring systems will record the voltage applied at the input terminals. In the first case the lack of damping will cause the response to oscillate forever, while the generator in the second case will match the lead, and the response will reproduce the applied voltage except for a minor distortion caused by the measuring system in the first part of the applied voltage.

So far, almost all analyses of measuring systems for impulse voltages have been based on specified input voltages regardless of whether, 


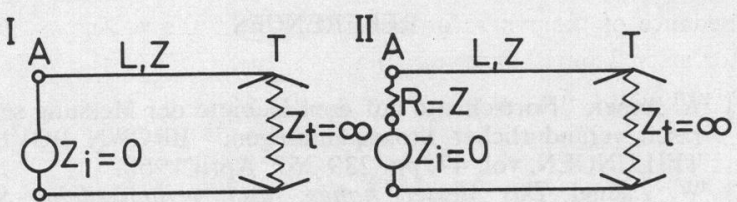

Voltage at A:

(a) 1

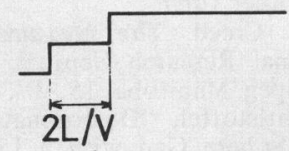

Voltage at $\mathrm{T}$ :

(b)
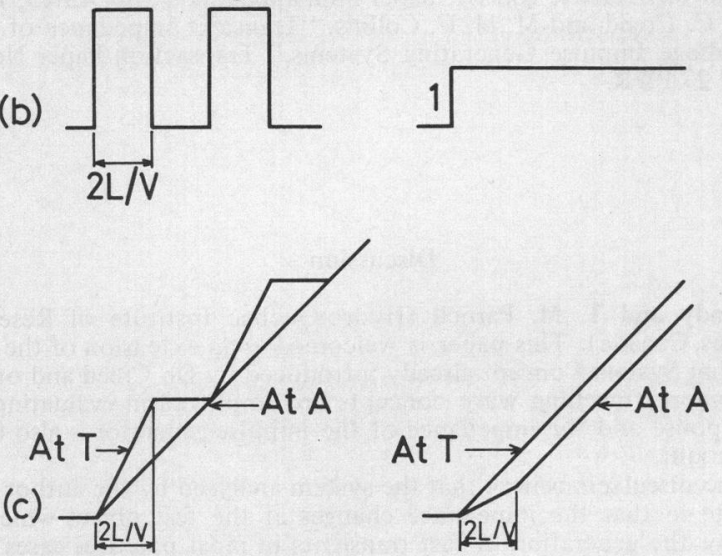

Fig. 9. Applied and measured voltages for the generator impedance $\mathrm{Z}_{\mathrm{i}}=0$ and $\mathrm{Z}_{\mathrm{i}}=\mathrm{Z}$.

on account of the "impedance" of the generator, such voltages can be generated. Measurements show that the "impedance", as seen from the input terminals of the measuring system, will usually be in the order of the surge impedance of the lead. Thus, the conditions in a practical impulse circuit will be similar to example II with the generator match-

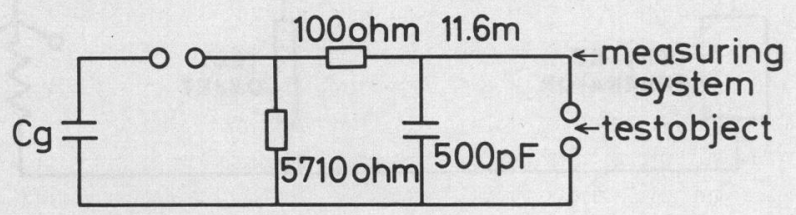

Fig. 10. Impulse circuit.

Table II. Data of the measuring systems A and B.

\begin{tabular}{l|c|c}
\hline & $\begin{array}{c}\text { Measuring Sy- } \\
\text { stem A. }\end{array}$ & $\begin{array}{c}\text { Measuring Sy- } \\
\text { stem B. }\end{array}$ \\
\hline $\begin{array}{l}\text { Damping resistor } \\
\text { in the lead }\end{array}$ & $424 \Omega$ & none \\
\hline Height (m) & 0.60 & 2.40 \\
\hline $\begin{array}{l}\text { Length of lead } \\
(\mathrm{m})\end{array}$ & 18.8 & 15.8 \\
\hline Resistance $(\Omega)$ & 10,000 & 8,976 \\
\hline $\mathrm{T}_{\infty}$ (ns) & 14 & 45 \\
\hline $\mathrm{T}_{\mathrm{N}}$ (ns) & 14 & -13 \\
\hline Divider ratio & 1475 & 922 \\
\hline
\end{tabular}

ing the lead and therefore differ very much from the conditions with a zero impedance generator.

This is illustrated by a measurement (fig. 10) with two different measuring systems. The data of the systems appear in table II, while their unit step responses are shown in fig. 11.

Due to the excellent response properties of system A the voltage measured by this system may be assumed to be identical with the applied voltage. The result of the measurement is shown in fig. 12 .
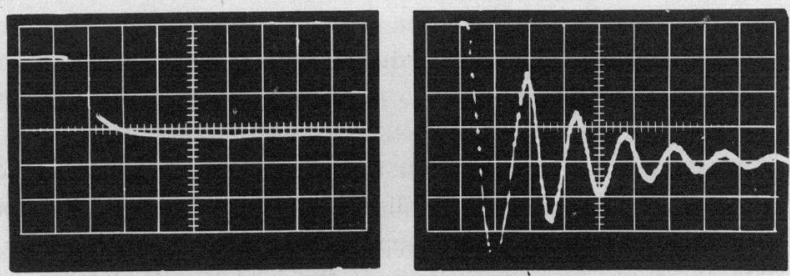

Fig. 11. Unit step responses of measuring systems A and B. System A: $\mathrm{x}: 20 \mathrm{~ns} / \mathrm{div}$ System B: $\mathrm{x}: 200 \mathrm{~ns} / \mathrm{div}$
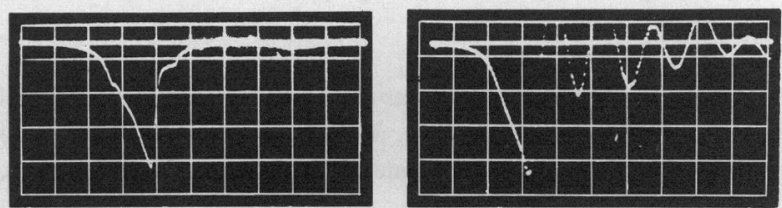

Fig. 12. Impulse voltages simultaneously measured with systems $\mathrm{A}$ and $\mathrm{B}$. System A: $\mathrm{x}: 200 \mathrm{~ns} / \mathrm{div}$ y: $36 \mathrm{v} / \mathrm{div}$
System B:

$\mathrm{x}: 200 \mathrm{~ns} / \mathrm{div}$

$\mathrm{y}: 60 \mathrm{v} / \mathrm{div}$
The fronts of the output voltages from the two systems for the simultaneously measured input voltage are nearly identical. The only explanation of this similarity is, that the generator circuit has an almost matching impedance which prevents oscillations caused by the lead of system B (cf. the unit step response, fig. 11). After the breakdown of the sphere gap the voltage measured with systems A and B will differ very much, since the impedance of the generator now will be almost equal to zero; (further examinations have shown that during the breakdown the sphere gap had an impedance of a magnitude of about $40 \Omega$ ).

The impedance of the impulse generator circuit is one of the problems in impulse measuring technique which are still not completely clarified, and which must be further investigated ${ }^{6}$.

\section{MEASURING SYSTEM PROPERTIES BASED ON RESPONSE CHARACTERISTICS}

The interaction between a physical phenomenon to be measured and the circuit (including the measuring system) in which the phenomenon appears, must be subjected to careful consideration before the design of any measuring system. Requirements of high limit frequency and great accuracy will usually cause a low impedance of the measuring system, and consequently the system will often be chosen on the basis of a compromise between a sufficiently fast measuring system and the tolerable load of the generating system. In the following paragraphs it is briefly described, how the responses and response times mentioned above determine the properties of the system.

\section{The Rapidity of the Measuring System.}

Measuring systems with high limit frequencies give unit step responses with steep fronts. A general requirement for the achievement of this is a small $\mathrm{T}_{\mathrm{kt}}$ and a small $\mathrm{T}_{\mathrm{t}}$. If the measuring lead is short $\left(2 \frac{\mathrm{L}}{\mathrm{v}} \ll \mathrm{T}_{\mathrm{kt}}\right)$ the importance of $\mathrm{T}_{\mathrm{kt}}$ will decrease, which in special cases can be used to raise the limit frequency. 
The time after which the response of the measuring system will follow an applied, linearly rising voltage depends on the internal impedance of the generator. If the generating circuit has a zero impedance, the unit step response must have reached its stationary value before this is complied with. In practical impulse circuits the value of the internal impedance, however, will be of the same magnitude as the surge impedance of the lead. If $Z_{\mathrm{g}}=\mathrm{Z}$, the required time is determined as the time when the "infinite-line" response has reached its stationary value, plus the time $2 \cdot \frac{\mathrm{L}}{\mathrm{V}}$. If $Z_{\mathrm{g}}$ is different from $\mathrm{Z}$ (e.g. $Z_{\mathrm{g}}=1 / 2 \mathrm{Z}$ ), the oscillations this causes in the response will be almost damped out after 3-4 reflections. This time should therefore be used instead of the time for the "infinite-line" response to reach its stationary value, provided that the time for 3-4 reflections is the greater.

The steepness of the "infinite-line" response can be described by $T_{\infty}$ (the steeper response, the smaller $T_{\infty}$ ), whereas there is no immediate relation between the front steepness of the unit step response and $\mathrm{T}_{\mathrm{N}}$. Moreover, $\mathrm{T}_{\infty}$ is independent of the lead length and presents a better means for the evaluation of a measuring system than does $T_{N}$.

\section{Measuring Error of the Measuring System in Case of Linearly Rising Voltages.}

The measuring error in measurements of linearly rising voltage. after a certain time is determined, as stated earlier, by the steepness of the voltage $S$ and the response time for the measuring system, $T_{N}$, as:

$$
\triangle=\mathrm{S} \cdot \mathrm{T}_{\mathrm{N}}
$$

If this relation shall be applicable in the determination of the true voltage across the test object in case of breakdown, it must be possible to establish the true time for the breakdown by means of the recorded wave. As shown earlier, the determination of this time is readily made if the steepest part of the unit step response of the measuring system is situated at the beginning of the unit step response.

\section{The Load Impedance of the Measuring System.}

The permissible magnitude of the load impedance of the measuring system depends on the actual task. In some cases a constant load of the test object is desired. In such cases the measuring system must employ a terminator with an impedance constantly equal to the surge impedance of the lead, or a lead so long that $2 \frac{\mathrm{L}}{\mathrm{V}}$ is greater than the time for which the load must be constant.

In many cases a low load of the test object is desired. For 2 times the travel time on the lead the impedance of the measuring system will in any case be equal to the surge impedance of the lead. Consequently, the lead should be as short as possible (or if necessary excluded) in order to reduce the time in which the measuring system represents a low impedance. It is further required, in order to attain a low load, that the terminator has a high resistance and a small $\mathrm{T}_{\mathrm{kt}}$.

\section{CONCLUSION}

The unit step response and the corresponding response time of the modified measuring system (often erroneously stated as the unit step response and response time of the measuring system) have been the only quantities so far used to describe the dynamic properties of a measuring system. In general it will be possible to obtain sufficient information about the system, if the unit step response of the modified system (including the lead length) and the "infinite-line" response are known. If, moreover, the reflection response is known, all the properties of the measuring system will be determined with an accuracy that will suffice for all practical purposes.

\section{REFERENCES}

[1] A. Asner, "Fortschritte auf dem Gebiete der Messung sehr hoher, rasch veränderlicher Stossspannungen," BROWN BOVERI MITTEILUNGEN, vol. 47, pp. 239-267, April 1960.

[2] W. Zaengl, Das Messen hoher, rasch veränderlicher Stossspannungen. Dissertation, Technischen Hochschule, Munich 1964.

[3] F. C. Creed, T. Kawamura and G. Newi, "Step Response of Measuring Systems for High Impulse Voltages," IEEE TRANS. POWER APPARATUS AND SYSTEMS, vol. 86, pp. 1408-1420, November 1967.

[4] F. C. Creed, The Measurement Problem in Impulse Testing. National Research Council, Ottawa, Canada. EHV Symposium, Winnipeg, Manitoba, 15.-17. September 1966.

[5] M. Christoffel, "Determination of the Sparkover Characteristics of a Sphere Gap with a Lineary Rising Steep-fronted Impulse Wave of Negative Polarity $(\mathrm{s}=60 \mathrm{~mm}-\mathrm{D}=250 \mathrm{~mm})$," CIGRE, 21st MEETING, vol. III, paper 333, appendix V, pp. 43-45, 1966.

[6] F. C. Creed and M. M. C. Collins, "Transient Impedance of High Voltage Impulse Generating Systems," Transaction Paper No. 70 TP 27-PWR.

\section{Discussion}

G. Karady and T. M. Parnell (Hydro-Quebec Institute of Research, Varennes, Canada): This paper is welcomed as an extension of the total measuring System Concept already introduced by Dr. Creed and others. Furthermore travelling wave concepts are employed in evaluating system response and the impedance of the impulse generator is also taken into account.

The discussers believe that the system analysed by the author is incomplete in that the impedance changes at the test object which accompany the generation of fast transients in most practical cases have not been specifually included in the analysis. The Bewley chart for an impulse test circuit is shown in Fig. 1 where it is assumed that breakdown of the test object occurs at time $\tau$. Not only does occurence of breakdown result in the injection of a new signal into the system it also radically changes the reflection coefficient at the test object $\mathrm{T} / 0$.

The task now is to evaluate the voltage at T/0 using only the information available at the voltage divider VD. The diagram indicated the complexity of this problem in which quite clearly the lead lengths,
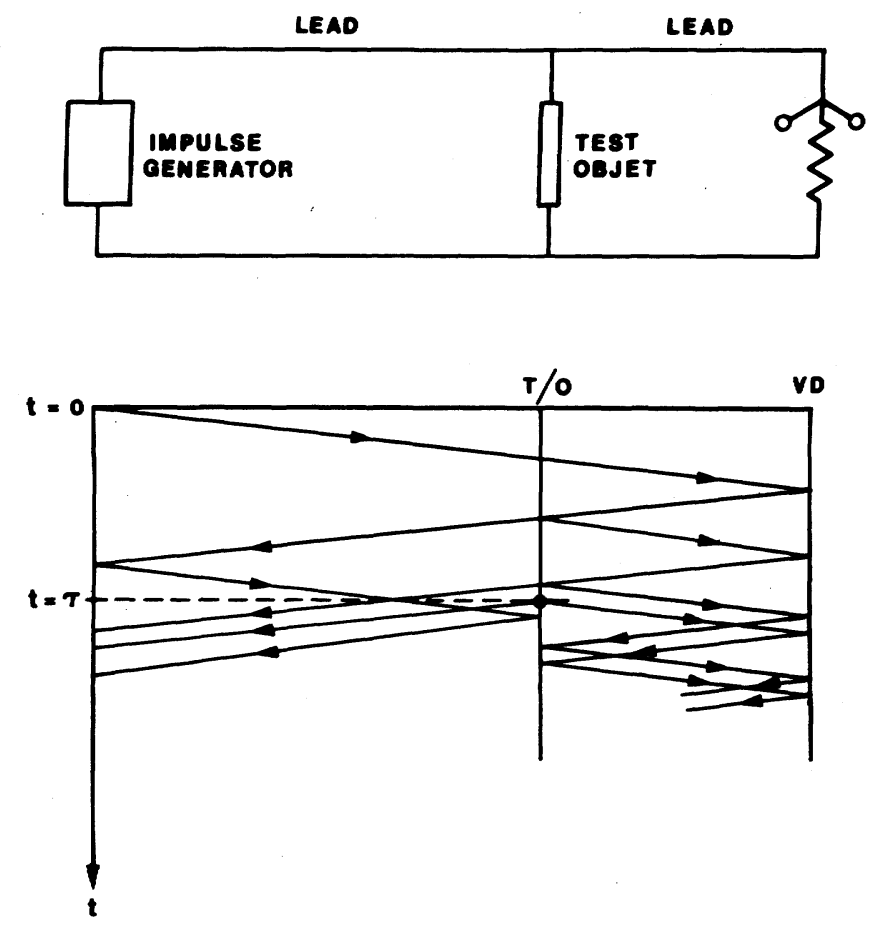

Fig. 1.

Manuscript received July 29, 1970. 
the generator, test object and divider impedances and the instant of flashover of the test object will all affect the result.

Would the authors comment on our suggestion and if appropriate suggest means of extending their own analysis to include the effects outlined above.

W. Zaengl (Eidg. Technische Hochschule, Zurich, Switzerland): The authors are to be congratulated for their clarifying presentation of the dynamic properties of impulse measuring systems, which are generally well known and have been discussed for some time. I would like to offer however some remarks on several items:

a) Leads to impulse voltage dividers should not have too small diameters due to the corona which might occur by applying high impulse voltage. Though it will be very difficult to avoid corona-effects with very high voltages in the order of some million of volts, a lead diameter in the order of 5 to 10 centimeters is sufficient to get a corona-free lead for voltages up to about $1 \mathrm{MV}$. This voltage level may be applicable by measuring very steep impulse-voltages which are chopped within short times in the order of $100 \mathrm{nsec}$, for which the dynamic properties of the measuring systems are of fundamental importance. The surge impedance $Z$ of those leads is generally much lower than $400-500 \Omega$, a value which is given by the authors.

As the surge impedance may be calculated with a yery good accuracy by

$$
\mathrm{Z}=\frac{\mathrm{L}}{\mathrm{V} \cdot \mathrm{C}}: \quad \begin{array}{ll}
\mathrm{L} & \begin{array}{l}
\text { length of the lead } \\
\text { velocity of light } \\
\text { capacity of the lead with the }
\end{array} \\
\mathrm{C} & \begin{array}{l}
\text { length } \mathrm{L}
\end{array}
\end{array}
$$

when the lead is in a position given by the measurement circuit, the quantity of $C$ governs the value of $Z$. The value of $C$ can be calculated mathematically also for special arrangements, which is shown in ref. 1.

b) In agreement to the authors it will be impossible to pinpoint the correct time for a breakdown in an impulse voltage generating system used for the determination of the response time $\mathrm{T}_{\mathrm{N}}$ by means of the CIGRE volt-time curve (see Fig. 5), if the measuring system would have a unit step response as shown for the idealized system I in Fig. 6 of the paper. In practice however, a measuring system with such an extraordinary unit step response should be rejected. It is true however, that unit step response of all measuring circuits, measured in the arrangement shown in Fig. 7, especially with the modification of the circuit by a vertical lead, will have a voltage time curve a little bit similar to Fig. 6 , System I. The amplitude of the voltage within the time $T_{1}$ however is only in the region of some percent of the steady state value and is generated without exception by the electric and magnetic fields, which are connected with the travelling waves running up the vertical lead. These fields induce this voltage in the divider system and the time $T_{1}$ is always the time difference between the two possible travel paths of the two voltage modes, the one following the leads to the divider, and the other using the shortest distance between the voltage generator located at the input end of the vertical lead. This "pick-up" or induced voltage is actually one of the largest disadvantages of using the arrangement of Fig. 7 for response time measurements, as it is not known whether this part of the unit step response is efficient in a practical impulse voltage generating and measuring circuit with a test object of any construction or not. I have proposed therefore a circuit for measuring the unit step response of impulse measuring circuits, using no vertical lead, which can be used in almost every high voltage laboratory by elevating the square wave generator to the input end of the horizontal lead to the divider (see Ref. 2).

c) Referring to item 4 and 5 of the paper I agree with the authors that the interaction between the generating and measuring systems determine the voltage across the test object, i.e. the output voltage of the generator or the input voltage of the measuring system. Due to this fact also, oscillations within the whole systems are excited or damped by the impedances and resistances which are effective in the system. I don't like, however, the statement, that generators with finite internal impedances $Z_{\mathfrak{i}}$, which can be defined by splitting up the generating system into a zero impedance voltage source $U_{g(s)}$ and the impedance $\mathrm{Z}_{\mathrm{i}(\mathrm{s})}$ in series, are damping the oscillations of the unit step response of the measuring system. It must be pointed out that there is only one unit step response of a system, which is defined by applying a unit step voltage at the input of the system. If the input impedance of this system is not constant, but time - or frequency - dependent, the input step voltage can only be produced with a zero impedance generator. If the input impedance of a measuring system is constant, however, a generator with finite internal and constant impedance can be used also for a correct unit step response measurement. This technique is usually applicable in low voltage high frequency systems which are used, for

Manuscript received August 11, 1970; revised March 24, 1971. instance, in communication systems. An impulse voltage measuring system, however, does not have a constant input impedance, and therefore only a zero impedance unit step voltage generator gives the true unit step response. Therefore, the statement that the oscillations on the unit step response will disappear by using a generator with an internal impedance equal to the surge impedance is wrong, as this response is no longer a unit step response. This response becomes now the unit step response of the measuring system, which is changed by adding in this special case a resistor to the input terminals with a value equal to the surge impedance of the lead.

The true interaction between measuring and generating system is given by the variation of the output voltage of the generating system due to the input impedance of the measuring system. All considerations given in this paper dealing with the measurement of linearly rising voltages and the time to the steady state value of the unit step response are only applicable to the measurement of idealized linearly rising voltages at the test object, generated by an impulse voltage generator with or without internal impedance. But where is the surge generator which has a linearly rising voltage, especially at the starting point of the voltage? As - it is not possible, due to the loss of information in a measuring system, to calculate or to determine the input voltage from the output voltage without the knowledge of the general shape of this input voltage, the transfer properties of the measuring system should be as simple as possible. And therefore, it would be more convenient for many applications to have a measuring system without strong oscillations. This means that the lead to a divider should always be damped with a resistor at the input end of the lead, which should not be as large as the surge impedance to get a very good transient response. Basic investigations due to damped lead systems are published in ref. 3 .

\section{REFERENCES}

[1] W. Zaengl: Kapazität eines Zylinders gegen senkrechtaufeinander stehende Ebenen. ATM - Blatt Z 130 - 3 (April 1969)

[2] W. Zaengl: Ein Verfahren zur Ermittlung der vollständigen Uebertragungseigenschaften eines Stosspannungsmesskreises. ETZ-A 90 (1969), S. 457 - 462

[3] W. Zaengl: Der Stosspannungsteiler mit Zuleitung Bull. SEV Vol. 61 (1970) (will be published)

Aa. Pedersen and P. Lausen: We wish to express our appreciation of the contributions to the discussion of our paper.

The solution of the problems involved in impulse measuring technique has made great progress during the last decade resulting in a clarification of a great number of the problems involved, although many questions, as pointed out in the discussion, still remain unclarified calling for a continuation of the research in this field.

The authors agree with Dr. Zaengl that the surge impedance of measuring leads for measuring systems up to some MV may be lower than 400-500 $\Omega$. It is quite true that a bigger lead diameter will cause a lower surge impedance, but at the same time as the voltage increases for high-voltage systems the height of the lead above the ground will also increase and thus to some extent counteract the decrease of the surge impedance. We think, however, that surge impedances lower than $300 \Omega$ are seldom found in high-voltage measuring systems.

The aim of showing the two stylized unit-step responses in fig. 6 was to demonstrate the principal effect of the shapes of the step response. Naturally, we agree that system 1 cannot be recommended for fast impulse measurements. The authors, however, do not agree with Dr. Zaengl that the foot on a step response "without exception" is caused by the electromagnetic field of a travelling wave running up the vertical lead. Anyhow this explanation is far too simplified. We agree that all phenomena are basically caused by electromagnetic fields but not in a simple way, and depending on the shape a foot on the response can be generated in many other ways.

Cơncerning the proposed set-up of the square wave generator we feel that it might give a step response for the measuring system closer to the true step response. However, in neither of the set-ups the true step response is determined. In our case the measuring system has been modified by the vertical lead, and in the other case the ground system has been modified by the addition of a vertical plane to the ground plane. Thus, the square wave generator has not been connected to the terminals of the measuring system in either of the cases. The response time, however, can be corrected for the effect of the vertical lead, whereas no correction can be applied for the effect of the vertical plane.

Dr. Zaengl's remarks concerning the unit-step response we think must be caused by a linguistic misunderstanding between Dr. Zaengl and us. We quite agree that there is only one unit-step response for the measuring system. The discussion in the paper concerning the inter- 
action between the impedances of the generating and measuring systems and of the conditions of producing a desired voltage (e.g. a step) at the input terminals of the measuring system in fact gave exactly the results Dr. Zaengl is pointing out. The misunderstanding may be cleared, if one bears in mind that theinfinite-line response for a two-component system equals the unit-step response for a three-component system which is composed of the two-component system and an ideal damping resistor equal to the surge impedance of the measuring lead placed at the input end of the measuring lead. Regardless of the apparent similarity between the two systems it must be remembered that the measuring properties of the two systems are fundamentally different.

The generation of a true linearly rising voltage (a ramp) requires in the same way as for the generation of a step voltage a zero impedance source. A measuring system with a ringing step response will give rise to a ringing response to a ramp. However, a linearly rising voltage from a normal impulse circuit will exhibit some deviation from the ramp around the beginning of the impulse similar to the second case in fig. 9. The response to this voltage will normally exhibit no oscillations due to the influence of the impedance of the generator, as demonstrated by the oscillograms in fig. 11 and 12 and explained e.g. in lit. 6: thus for a lot of practical cases the measuring system even with heavy ringing step responses will cause no oscillations on the voltage. For such cases there will consequently be no advantage in adding a damping resistor as suggested by Dr. Zaengl. In measurements of linearly rising voltages which are suddenly chopped a damping resistor can in fact entail a disadvantage because it will reduce the limit frequency for the measuring system. It is obvious, however, that the damping resistor is advantageous for measurements of voltages after the instant of chopping at which the impedance of the test object changes to nearly zero.

Dr. Parnell and Mr. Karady have raised the question of the interaction between the "time-dependent impedances" of the generator, test object, and measuring system, and have set up a Bewley chart for illustration purposes. As stated, this chart shows the complexity of the problems. Furthermore, the reflection coefficients at all the discontinuity points (at the test object, terminator, impulse generator, etc.) are "time-dependent" which add drastically to the complexity. This means that the Bewley chart cannot be used in practice for evaluation of the test voltage. In many cases, however, the main problem is to make sure that the test voltage at a certain time before breakdown is linear. This is possible by using the information contained in the step response and in the output oscillogram from the measurement, a procedure which is suggested for the new IEC standards for High-Voltage Test Techniques. The determination of the instant of chopping can be similarly made provided that the chop is instantaneous, corresponding to an instantaneous change of the impedance of the test object to zero. This presupposition seems to be relatively well fulfilled for test objects such as sphere gaps, whereas it is more doubtful whether the presuppo- sition is fulfilled for rod gaps for which the rate of collapse is smaller. Investigations of the influence of the different components in the impulse circuit have already been undertaken (lit. 6). Such investigations should be continued and extended to include the determination of the rate of collapse for different gaps and the influence of the different components hereon. The clarification of these problems is the aim of a current investigation in our laboratory.

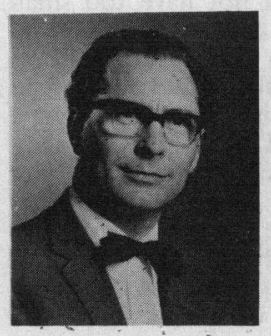

Aa. Pedersen (SM'70) was born in Randers, Denmark, in 1930. He received the M.Sc. degree from the Technical University of Denmark, in 1956.

From 1957 to 1959 he was an Assistant Professor at the Electrotechnical Laboratory, Technical University of Denmark. He has been involved in studies in the field of high voltage technique at ASEA, Sweden, the National Bureau of Standards, General Electric Company, and Ohio Brass Company, and the National Research Council, Canada, from 1959 to 1961 . He then became in charge of the planning and establishment of a new high voltage laboratory at the Electric Power Engineering Department, Technical University of Denmark. Since 1961 he has been Associate Professor in charge of this laboratory.

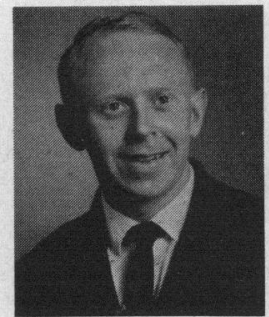

P. Lausen was born in R $\phi$ dby, Denmark in 1940. $\mathrm{He}$ received the M.Sc degree from the Technical University of Denmark, in 1966.

In 1967 he was employed as Graduate Instructor in teaching and research at the High Voltage Laboratory. Since 1969 he has been working toward the Ph.D. degree there. 